COMPOSITES SCIENCE AND TECHNOLOGY

VOLUME 77, 22 MARCH 2013, PAGES 67-73

http://dx.doi.org/10.1016/j.compscitech.2013.01.006

http://www.sciencedirect.com/science/article/pii/S0266353813000122

\title{
FIBER ASSOCIATION AND NETWORK FORMATION IN \\ PLA/LIGNOCELLULOSIC FIBER COMPOSITES
}

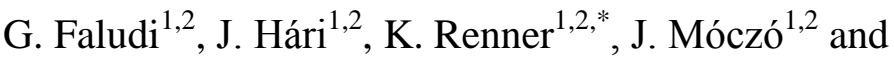 \\ B. Pukánszky ${ }^{1,2}$
}

${ }^{1}$ Laboratory of Plastics and Rubber Technology, Budapest University of Technology and Economics, H-1521 Budapest, P.O. Box 91, Hungary

${ }^{2}$ Institute of Materials and Environmental Chemistry, Research Centre for Natural Sciences, Hungarian Academy of Sciences, H-1525 Budapest, P.O. Box 17, Hungary

*Corresponding author: Phone: +36-1-463-2967, Fax: +36-1-463-3474, Email: krenner@mail.bme.hu

\section{ABSTRACT}

PLA composites were prepared in an internal mixer with a lignocellulosic fiber having relatively large aspect ratio. Fiber content changed between 0 and 60 vol\% and the homogenized material was compression molded to $1 \mathrm{~mm}$ thick plates. The composites showed anomalous behavior above certain fiber content. Their modulus and especially their strength decreased drastically and modeling also proved the loss of reinforcement at large fiber contents. Micromechanical testing showed that the mechanism of deformation and failure changes at a critical fiber content. Microscopic analysis indicated the formation of a network purely from geometrical reasons. The inherent strength 
of the network is very small because of the weak forces acting among the fibers. This weak inherent strength makes the structure of the composites very sensitive to processing conditions, and decreases strength, reproducibility as well as reliability.

KEYWORDS: A. short-fibre composites, B. mechanical properties, C. damage mechanism, C. failure criterion, network formation 


\section{INTRODUCTION}

The production of PLA and its use in all areas of life increase with a high rate. PLA has many advantageous properties, but also some drawbacks, which are often counterbalanced by modification. Plasticization [1-5], copolymerization [6-11], chemical modification [12], blending $[13,14]$ are all used to adjust the properties of the polymer to the intended application. When PLA is used as structural material, its stiffness and strength can be improved by the incorporation of fillers or reinforcing fibers. Natural reinforcements are especially advantageous, since they result in composites with large stiffness, acceptable strength and the composite is even compostable [15-17], which is an important advantage for most plastic materials.

Aggregation is always an issue for composites containing a large amount of fillers or fibers [18-22]. Aggregation depends on the ratio of adhesion and separation forces, the first being related to the surface energy of the components and particle size, while the second to shear forces acting during homogenization [23]. Lignocellulosic fibers, most of all wood, are usually quite large and their surface energy is small [24,25], thus the homogeneous distribution of the fibers is relatively easy in the matrix. Additionally, their aspect ratio is not very large, usually between 1 and 10, thus structural effects like aggregation and orientation are often limited in their composites. In fact, structural effects are discussed relatively seldom in the literature. For example, Drzal et al. [26-28] mentioned in some of their papers that the aggregation of wood fibers resulted in inferior properties. Occasionally non-reactive surface modification is used to facilitate processing and avoid aggregation [29-31]. However, structural effects depend very much on component properties and processing conditions thus each composite must be considered individually from this respect.

In a detailed study we compared six lignocellulosic fibers in PLA to determine the effect of fiber characteristics on composite properties [32]. Aspect ratio and particle size proved to influence properties considerably and contrary to many claims published in the literature [15,33-41] we found that interfacial adhesion is rather strong between PLA and lignocellulosic fibers. As a consequence, usually the fracture of the fibers is 
the dominating micromechanical deformation process, which determines composite strength. In the case of one or two fibers, we observed anomalous behavior, which apparently resulted from structural phenomena [42]. Further experiments were carried out proving that under certain conditions fibers may interact with each other and this interaction results in the drastic decrease of composite strength. The goal of this paper is to report some of these results and call attention to a structural phenomenon rarely discussed in the literature.

\section{EXPERIMENTAL}

The PLA used in the experiments was the Ingeo 4032D grade $\left(M_{n}=88500\right.$ $\mathrm{g} / \mathrm{mol}$ and $\mathrm{M}_{\mathrm{w}} / \mathrm{M}_{\mathrm{n}}=1.8$ ) purchased from NatureWorks (USA) recommended for extrusion by the producer. The polymer ( $<2 \% \mathrm{D}$ isomer) has a density of $1.24 \mathrm{~g} / \mathrm{cm}^{3}$, while its MFR is $3.9 \mathrm{~g} / 10 \mathrm{~min}$ at $190{ }^{\circ} \mathrm{C}$ and $2.16 \mathrm{~kg}$ load. The composites, in which the structural effect was observed, were prepared with the Arbocel FT400 grade lignocellulosic fibers supplied by Rettenmaier and Söhne GmbH, Germany. The fiber has an average particle size of about $170 \mu \mathrm{m}$, average length and thickness of 235 and $22 \mu \mathrm{m}$, respectively, resulting in an aspect ratio of 12.6. The Filtracel EFC 1000 wood fiber (average size: $210 \mu \mathrm{m}$, aspect ratio: 6.8) from the same supplier was used as reference filler, which did not produce the same structural effect. SEM micrographs showing particles of the two fibers are presented in Fig. 1. Particle characteristics were determined quantitatively by laser light scattering, but also by image analysis from SEM micrographs.

Poly(lactic acid) were dried in vacuum oven while the fibers were dried in drying oven before composite preparation $\left(110^{\circ} \mathrm{C}\right.$ for 4 hours and $105^{\circ} \mathrm{C}$ for 4 hours, respectively). The components were homogenized using a Brabender W 50 EHT internal mixer at $180{ }^{\circ} \mathrm{C}, 50 \mathrm{rpm}$ for $10 \mathrm{~min}$. Fiber content changed from 0 to $60 \mathrm{vol} \%$ and three series of composites were produced from the FT400 fiber to confirm the existence of the phenomenon observed and to check the reliability of the measurements. The homogenized material was transferred into a frame of $320 \times 240 \times 1 \mathrm{~mm}$ dimensions placed between two steel plates. It was compression molded to $1 \mathrm{~mm}$ thick plates at $190{ }^{\circ} \mathrm{C}$ with 
$3 \mathrm{~mm}$ preheating and $3 \mathrm{~mm}$ molding time using a Fontijne SRA 100 machine. The specimens cut from the plates were kept in a room with controlled temperature and humidity $\left(23{ }^{\circ} \mathrm{C}\right.$ and $50 \%$ ) for at least two weeks prior further testing.

Mechanical properties were characterized by the tensile testing of specimens cut from the $1 \mathrm{~mm}$ thick plates using an Instron 5566 apparatus. The measurements were done at $5 \mathrm{~mm} / \mathrm{min}$ cross-head speed and $115 \mathrm{~mm}$ gauge length. Micromechanical deformation processes were followed by acoustic emission (AE) measurements. A Sensophone AED 40/4 apparatus was used to record and analyze acoustic signals generated during tensile testing. The particle characteristics of fibers and the structure, as well as the deformation mechanism of the composites were studied by scanning electron microscopy, SEM (JEOL JSM-6380 LA). Micrographs were recorded on tensile fracture surfaces. Polarization optical microscopy (POM) was also carried out to determine fiber distribution in the composites. Slices of about $2.5 \mu \mathrm{m}$ thickness were cut from the compression plates parallel with its plane and then micrographs were taken from them at various magnifications.

\section{RESULTS AND DISCUSSION}

The results are discussed in several sections. First we present composite properties and call attention to anomalies in their composition dependence. Micromechanical deformations are analyzed next and structural reasons resulting in the anomalies are discussed in the final section.

\subsection{Properties}

The composition dependence of stiffness is shown in Fig. 2 for composites prepared with the reference wood flour and for the three series prepared with the fiber having relatively large aspect ratio. The modulus of the reference composite is smaller at most compositions than that of the other three composites and increases continuously with increasing fiber content, as expected. Standard deviation is slightly larger at large fiber loadings and the last points might deviate a little from the general tendency, but 
structural effects are not evident on the correlation. The larger stiffness of the other three composites can be explained with the larger aspect ratio (12.6 vs. 6.8) of the fiber, and that is also expected. However, above 0.4 volume fraction fiber content stiffness deviates from the general tendency and the deviation increases with increasing fiber content. Since fiber orientation must be approximately the same in all composites and modulus is not very sensitive to aggregation, the structural effect causing the deviations must be severe.

The effect is demonstrated very well by Fig. 3 presenting the composition dependence of tensile strength for the four series. Strength decreases continuously with a relatively small slope in the case of the reference material. The stronger reinforcement of the fiber with the larger aspect ratio is quite evident from the figure; at small fiber contents the strength of the composites exceeds significantly that of the reference material. However, between 0.3 and 0.5 volume fraction fiber content strength drops drastically for all three series for some reason, which at this point is not quite evident. We may assume with quite strong certainty, though, that a new process initiated by a structural effect results in the premature failure of the composites. We must call the attention here to the fact that differences among the three series are quite large both in the absolute value of strength and in the composition at which the drastic decrease of strength occurs. The differences among the series are much smaller in the composition dependence of modulus. The larger deviation indicates that the effect causing them depends very much on processing conditions and must have changed from one series to the other in spite of all efforts to use completely identical conditions for sample preparation.

The reinforcing effect of the fibers can be estimated quantitatively by the simple model [43], which describes the composition dependence of strength (Eq. 1)

$$
\sigma_{T}=\sigma_{T 0} \lambda^{n} \frac{1-\varphi}{1+2.5 \varphi} \exp (B \varphi)
$$

where $\sigma_{T}$ and $\sigma_{T 0}$ are the true tensile strength $\left(\sigma_{T}=\sigma \lambda\right.$ and $\left.\lambda=L / L_{0}\right)$ of the composite and the matrix, respectively, $n$ is a parameter expressing the strain hardening tendency of the matrix, $\varphi$ is the volume fraction of the fiber and $B$ is related to its relative load- 
bearing capacity, i.e. to the extent of reinforcement. If the natural logarithm of reduced strength is plotted against the volume fraction of the fiber we should obtain a straight line

$$
\ln \sigma_{\text {Tred }}=\ln \frac{\sigma_{T}}{\lambda^{n}} \frac{1+2.5 \varphi}{1-\varphi}=\ln \sigma_{\mathrm{TO}}+B \varphi
$$

the slope of which gives reinforcement, the load carried by the fiber. However, besides calculating $B$, the lines offer additional information, since any deviation from the linear correlation indicates structural effects very sensitively. The strength of the four series of composites is plotted in the form of Eq. 2 in Fig. 4. The correlation is perfectly linear for the reference filler indeed, and also for the other three series at small fiber contents, but large deviations occur for larger filler loadings in the case of the latter three. The deviations are always negative indicating that the effect in question leads to poor strength and premature failure.

\subsection{Micromechanical deformations}

In heterogeneous materials stress concentration develops around the heterogeneities under the effect of external load. Stress maxima initiate local deformation processes, some of which can be followed by acoustic emission measurements. Burst like processes, like debonding or fiber fracture, are accompanied by elastic waves which can be picked up by piezoelectric sensors. We hoped that eventual changes in local processes offer us further information about the structure and failure mechanism of our composites.

The result of an acoustic emission measurement is presented in Fig. 5. Small circles indicate individual acoustic events and the steeply increasing trace gives the cumulative number of signals recorded during the measurement. The stress vs. strain trace of the material is also included as reference. We can see that acoustic activity starts after a certain deformation and then the number of events increase steeply with elongation. The shape of the cumulative number of signal trace allows us the determination of a characteristic elongation $\left(\varepsilon_{\mathrm{AE}}\right)$ and stress $\left(\sigma_{\mathrm{AE}}\right)$ value, which correspond to the initiation of the 
dominating local deformation process. Earlier investigations showed that in the case of the FT400 fiber used in this study, this process is the fracture of the fibers perpendicular to their axis.

The experiment, the result of which is presented in Fig. 5 was carried out at 5 vol\% fiber content. All results presented in Figs. 2-4 indicated that dispersion is good in this composite and structural effects are absent. On the other hand, deviation in modulus and a drastic drop in strength were observed in the range of 30-50 vol\% fiber content. The results of an acoustic emission experiment carried out on a composite containing 50 vol\% fiber is presented in Fig. 6 using the same scale as in Fig. 5. We can clearly see that the number of signals is very small; most of them develop at failure and not during the preceding elongation of the specimen. The lack of signals indicates a drastic change in failure mechanism or at least in its initiation. The dominating local deformation process occurs very easily at very small stress. We can also see that although the shape of the cumulative number of signal trace is very similar in the two cases presented (see Figs. 5 and 6 - see also the inset), initiation deformation and the number of signals change considerably. Cumulative number of signal traces measured at different fiber contents are compared in Fig. 7. Initiation deformation decreases continuously with increasing fiber content up to $20 \mathrm{vol} \%$ in this series, and then a sudden drop occurs above this fiber loading without any detectable correlation between $\varepsilon_{\mathrm{AE}}$ and fiber content. The figure confirms again that the mechanism of deformation and failure obviously changes at around $30 \mathrm{vol} \%$ fiber content in this composite series.

Fig. 8 presenting the composition dependence of the characteristic stress determined in the way shown in Fig. 5 supplies a further proof for the change in local deformation processes. Similarly to tensile strength, characteristic stress decreases slightly with increasing fiber content for the reference composite containing the EFC 1000 fiber. Earlier experiments proved that this fiber fractures parallel to its axis during deformation which leads to the failure of the composite. At small fiber content, characteristics stress measured in the other three composites is larger, exceeds $50 \mathrm{MPa}$, since the main local process generating acoustic signals is the fracture of the fibers perpendicular- 
ly to their axis. However, at large fiber content $\sigma_{\mathrm{AE}}$ decreases drastically showing a change in mechanism, which obviously cannot be the fracture of the fibers. We may assume at this point that the fibers form aggregates or a network and the break down of this network results in the failure of the composite, but we need additional proof to support this speculation.

\subsection{Structure}

SEM and POM was used for the characterization of the structure of the composites. SEM could not offer much information about the distribution of the fibers independently of the preparation method of the fracture surface. Micrographs were recorded on surfaces created by fracture at liquid nitrogen temperature or by tensile fracture. On the other hand, optical micrographs showing a much larger area gave a clear picture on fiber distribution and structure formation. Fig. 9a shows a micrograph taken from a slice parallel to the plane of the compression molded plate from the composite containing 5 vol\% of the large aspect ratio fiber. The fibers are distributed completely independently of each other and they do not show any tendency for aggregation. The lack of structure formation through attractive interactions is further confirmed by the micrograph taken from the composite prepared with 20 vol\% fiber (Fig. 9b). Some fibers touch each other, but the distribution of the fibers is quite uniform and no aggregation whatsoever can be observed in the micrograph. On the other hand, at 40 vol\% fiber content the fibers overlap each other practically in the entire area photographed (Fig. 9c) and form some kind of a network. We cannot really call these contacts aggregation, since the distribution of the fibers and thus the network is completely homogeneous.

Network formation must result in the modification of properties and it really does as we saw in Figs. 2-4 and in the micromechanical response of the composites. Rheological properties usually indicate even more sensitively the interaction of fibers, or in fact any particles $[44,45]$. The torque recorded during the homogenization of the composites in the internal mixer is plotted against fiber content in Fig. 10 for the reference composite and for one of the series prepared with the fiber having the large aspect 
ratio. Torque increases with a moderate slope for composites containing the reference fiber and then it levels off. This leveling off may result from the increasing temperature caused by the larger friction in the composites containing more fibers. Torque is smaller for the FT400 fiber at small fiber contents, because of the orientation of the long fibers and due to frictional warming. However, above 0.3 volume fraction torque increases very steeply most probably because of the formation of the fiber network shown in Fig. 9c.

\subsection{Discussion}

In previous sections we showed that properties change drastically above a certain fiber content in composites containing a fibrous reinforcement with large aspect ratio. Micromechanical testing also confirmed the change of deformation and failure mechanism at the same fiber loading. Finally, microscopy proved the formation of a physical network of the fibers. The correlation between network formation and the deterioration of properties is completely clear, but a few questions remain open like the reason for the formation of the network and the strong variation in properties from one series of measurements to the other.

Aggregation and network formation are well known in particulate filled [18-21] and especially in nanocomposites $[46,47]$. This is usually brought about by the interaction of the particles. For example, edge-to-plate interaction created by the $\mathrm{OH}$ groups located on the edge of the platelets and the silicate surface in layered silicate nanocomposites was shown to lead to the formation of a house-of-card structure and the steep increase of viscosity $[45,48,49]$. Very small spherical particles also interact to form aggregates and above a percolation threshold they form a network with the same result [44,50,51]. However, in spite of the active $\mathrm{OH}$ groups on their surface, lignocellulosic fibers usually do not aggregate, because of their large size and small surface energy. On the other hand, maximum packing fraction is relatively small, 0.51 , at random orientation of the fibers [52], thus network formation can start locally at relatively small fiber content. So in our case the fibers touch each other from purely geo- 
metrical reasons and the resulting network deteriorates properties. The small strength, the small critical deformation and the low acoustic activity all prove that the forces holding the network together are weak, thus it fails even under the effect of limited load.

The weak interaction among the fibers and within the network justifies the strong variation both in properties and in critical fiber content from one series to the other. Although we did everything to prepare the composites exactly the same way in each series, small differences in feeding the material into the internal mixer and further processing by compression molding led to changes in structure and consequently in properties. Such a variation is unavoidable under the conditions used. Better distribution of fibers resulted in larger characteristic stress (Fig. 8), larger composite strength (Fig. 3) and a larger threshold concentration for network formation. Obviously structure development depends very much on processing technology for fibers with large aspect ratio, which must be always kept in mind in the development of an industrial process and in practical applications.

\section{CONCLUSIONS}

PLA composites reinforced with a fiber having large aspect ratio showed anomalous behavior above certain fiber content. The modulus and especially the strength of the composites decreased drastically and modeling also proved the loss of reinforcement at large fiber contents. Micromechanical testing showed that the mechanism of deformation and failure changes at this critical fiber content. Microscopic analysis indicated the formation of a network purely from geometrical reasons. The inherent strength of the network is very small because of the weak forces acting among the fibers. This weak inherent strength makes the structure of the composites very sensitive to processing conditions, and decreases strength, reproducibility as well as reliability. Processing conditions and composition must be selected very carefully when natural fibers with large aspect ratio are used for the preparation of composites. 


\section{ACKNOWLEDGEMENTS}

The authors are indebted to Zsolt László for his help in the determination of the particle characteristics of fibers and for Ágnes Gábor, Gábor Dora, Zoltán Link and Áron Csikós for the preparation of the composite samples. The research on heterogeneous polymer systems was financed by the National Scientific Research Fund of Hungary (OTKA Grant No. K 101124) and by the Forbioplast FP7 project of EU (212239); we appreciate the support very much. One of the authors (KR) is grateful also to the János Bolyai Research Scholarship of the Hungarian Academy of Sciences for its support.

\section{REFERENCES}

[1] Martin O., Averous L.: Poly(lactic acid): plasticization and properties of biodegradable multiphase systems. Polymer, 42, 6209-6219 (2001).

[2] Ljungberg N., Wesslen B.: Tributyl citrate oligomers as plasticizers for poly (lactic acid): thermo-mechanical film properties and aging. Polymer, 44, 7679-7688 (2003).

[3] Kulinski Z., Piorkowska E., Gadzinowska K., Stasiak M.: Plasticization of poly(Llactide) with poly(propylene glycol). Biomacromolecules, 7, 2128-2135 (2006).

[4] Pillin I., Montrelay N., Grohens Y.: Thermo-mechanical characterization of plasticized PLA: Is the miscibility the only significant factor? Polymer, 47, 4676-4682 (2006).

[5] Lemmouchi Y., Murariu M., Dos Santos A. M., Amass A. J., Schacht E., Dubois P.: Plasticization of poly(lactide) with blends of tributyl citrate and low molecular weight poly(D,L-lactide)-b-poly(ethylene glycol) copolymers. European Polymer Journal, 45, 2839-2848 (2009).

[6] Li B., Chen S. C., Qiu Z. C., Yang Q. K. K., Tang S. P., Yu W. J., Wang Y. Z.: Synthesis of poly(lactic acid-b-p-dioxanone) block copolymers from ring opening polymerization of p-dioxanone by poly(L-lactic acid) macroinitiators. Polymer Bulletin, 61, 139-146 (2008).

[7] Hirata M., Kimura Y.: Thermo mechanical properties of stereoblock poly(lactic acid)s with different PLLA/PDLA block compositions. Polymer, 49, 2656-2661 (2008).

[8] Ho C. H., Wang C. H., Lin C. I., Lee Y. D.: Synthesis and characterization of TPO-PLA copolymer and its behavior as compatibilizer for PLA/TPO blends. Polymer, 49, 3902- 
3910 (2008).

[9] Mert O., Doganci E., Erbil H. Y., Dernir A. S.: Surface characterization of poly(L-lactic acid)-methoxy poly(ethylene glycol) diblock copolymers by static and dynamic contact angle measurements, FTIR, and ATR-FTIR. Langmuir, 24, 749-757 (2008).

[10] Opaprakasit M., Petchsuk A., Opaprakasit P., Chongprakobkit S.: Effects of synthesis conditions on chemical structures and physical properties of copolyesters from lactic acid, ethylene glycol and dimethyl terephthalate. Express Polymer Letters, 3, 458-468 (2009).

[11] Namkajorn M., Petchsuk A., Opaprakasit M., Opaprakasit P.: Synthesis and characterizations of degradable aliphatic-aromatic copolyesters from lactic acid, dimethyl terephthalate and diol: Effects of diol type and monomer feed ratio. Express Polymer Letters, 4, 415-422 (2010).

[12] Hassouna F., Raquez J. M., Addiego F., Toniazzo V., Dubois P., Ruch D.: New development on plasticized poly(lactide): Chemical grafting of citrate on PLA by reactive extrusion. European Polymer Journal, 48, 404-415 (2012).

[13] Gu S. Y., Zhang K., Ren J., Zhan H.: Melt rheology of polylactide/poly(butylene adipate-co-terephthalate) blends. Carbohydrate Polymers, 74, 79-85 (2008).

[14] Rohman G., Laupretre F., Boileau S., Guerin P., Grande D.: Poly(D,Llactide)/poly(methyl methacrylate) interpenetrating polymer networks: Synthesis, characterization, and use as precursors to porous polymeric materials. Polymer, 48, 70177028 (2007).

[15] Mathew A. P., Oksman K., Sain M.: Mechanical properties of biodegradable composites from poly lactic acid (PLA) and microcrystalline cellulose (MCC). Journal of Applied Polymer Science, 97, 2014-2025 (2005).

[16] Iovino R., Zujjo R., Rao M. A., Cassar L., Gianfreda L.: Biodegradation of poly(lactic acid)/starch/coir biocomposites under controlled composting conditions. Polymer Degradation and Stability, 93, 147-157 (2008).

[17] Pradhan R., Misra M., Erickson L., Mohanty A.: Compostability and biodegradation study of PLA-wheat straw and PLA-soy straw based green composites in simulated composting bioreactor. Bioresource Technology, 101, 8489-8491 (2010).

[18] Rothon R.: Particulate-Filled Polymer Composites. Rapra Technology, Shrewsbury 
(2003).

[19] Ess J. W., Hornsby P. R.: Twin-Screw Extrusion Compounding of Mineral Filled Thermoplastics - Dispersive Mixing Effects. Plastics and Rubber Processing and Applications, 8, 147-156 (1987).

[20] Móczó J., Fekete E., Lászlo K., Pukánszky B.: Aggregation of particulate fillers: Factors, determination, properties. Macromolecular Symposia, 194, 111-124 (2003).

[21] Adams J. M., Mullier M. A., Seville J. P. K.: Agglomeration. in 'Tribology in particulate technology' eds.: Briscoe B. J. and Adams J. M.) Adam Hilger, Bristol, 375-389 (1987)

[22] Tabor D.: Powder Compaction and Interface Shear: Adhesion of solids. in 'Tribology in particulate technology' eds.: Briscoe B. J. and Adams J. M.) Adam Hilger, Bristol, 206$219(1987)$

[23] Adams J. M., Edmondson B.: Forces between particles in continuous and discrete liquid media. in 'Tribology in particulate technology' eds.: Briscoe B. J. and Adams J. M.) Adam Hilger, Bristol, 154-172 (1987)

[24] de Meijer M., Haemers S., Cobben W., Militz H.: Surface Energy Determinations of Wood: Comparison of Methods and Wood Species. Langmuir, 16, 9352-9359 (2000).

[25] Cordeiro N., Ornelas M., Ashori A., Sheshmani S., Norouzi H.: Investigation on the surface properties of chemically modified natural fibers using inverse gas chromatography. Carbohydrate Polymers, 87, 2367-2375 (2012).

[26] Liu W. J., Misra M., Askeland P., Drzal L. T., Mohanty A. K.: 'Green' composites from soy based plastic and pineapple leaf fiber: fabrication and properties evaluation. Polymer, 46, 2710-2721 (2005).

[27] Mohanty A. K., Tummala P., Liu W., Misra M., Mulukutla P. V., Drzal L. T.: Injection Molded Biocomposites from Soy Protein Based Bioplastic and Short Industrial Hemp Fiber. Journal of Polymers and the Environment, 13, 279-285 (2005).

[28] Huda M. S., Drzal L. T., Mohanty A. K., Misra M.: Effect of fiber surface-treatments on the properties of laminated biocomposites from poly(lactic acid) (PLA) and kenaf fibers. Composites Science and Technology, 68, 424-432 (2008).

[29] Raj R. G., Kokta B. V.: Mechanical-Properties of Surface-Modified Cellulose Fiber Thermoplastic Composites. Acs Symposium Series, 476, 76-87 (1992). 
[30] Raj R. G., Kokta B. V.: Reinforcing High-Density Polyethylene with Cellulosic Fibers .1. The Effect of Additives on Fiber Dispersion and Mechanical-Properties. Polymer Engineering and Science, 31, 1358-1362 (1991).

[31] Dányádi L., Móczó J., Pukánszky B.: Effect of various surface modifications of wood flour on the properties of PP/wood composites. Composites Part a-Applied Science and Manufacturing, 41, 199-206 (2010).

[32] Dora G., Faludi G., Imre B., Renner K., Móczó J., Pukánszky B.: PLA/Lignocelulosic Fiber Composites: Interfacial Adhesion and Failure Mechanism. Composites Part aApplied Science and Manufacturing, submitted, (2012).

[33] Bax B., Müssig J.: Impact and tensile properties of PLA/Cordenka and PLA/flax composites. Composites Science and Technology, 68, 1601-1607 (2008).

[34] Plackett D., Lřgstrup Andersen T., Batsberg Pedersen W., Nielsen L.: Biodegradable composites based on -polylactide and jute fibres. Composites Science and Technology, 63, 1287-1296 (2003).

[35] Huda M. S., Drzal L. T., Misra M., Mohanty A. K.: Wood-fiber-reinforced poly(lactic acid) composites: Evaluation of the physicomechanical and morphological properties. Journal of Applied Polymer Science, 102, 4856-4869 (2006).

[36] Huda M. S., Mohanty A. K., Drzal L. T., Schut E., Misra M.: "Green" composites from recycled cellulose and poly(lactic acid): Physico-mechanical and morphological properties evaluation. Journal of Materials Science, 40, 4221-4229 (2005).

[37] Oksman K., Skrifvars M., Selin J.-F.: Natural fibres as reinforcement in polylactic acid (PLA) composites. Composites Science and Technology, 63, 1317-1324 (2003).

[38] Bledzki A. K., Jaszkiewicz A., Scherzer D.: Mechanical properties of PLA composites with man-made cellulose and abaca fibres. Composites Part A: Applied Science and Manufacturing, 40, 404-412 (2009).

[39] Petinakis E., Yu L., Edward G., Dean K., Liu H. S., Scully A. D.: Effect of MatrixParticle Interfacial Adhesion on the Mechanical Properties of Poly(lactic acid)/WoodFlour Micro-Composites. Journal of Polymers and the Environment, 17, 83-94 (2009).

[40] Sykacek E., Hrabalova M., Frech H., Mundigler N.: Extrusion of five biopolymers reinforced with increasing wood flour concentration on a production machine, injection moulding and mechanical performance. Composites Part A: Applied Science and Manu- 
facturing, 40, 1272-1282 (2009).

[41] Suryanegara L., Nakagaito A. N., Yano H.: The effect of crystallization of PLA on the thermal and mechanical properties of microfibrillated cellulose-reinforced PLA composites. Composites Science and Technology, 69, 1187-1192 (2009).

[42] Faludi, G., Dora, G., Renner, K., Móczó, J., Pukánszky, B.: Biocomposite from polylactic acid and lignocellulosic fibers: Structure-property correlations. Carbohydrate Polymers, 92, 1767-1775 (2013).

[43] Pukánszky B.: Influence of Interface Interaction on the Ultimate Tensile Properties of Polymer Composites. Composites, 21, 255-262 (1990).

[44] Kiss A., Fekete E., Pukánszky B.: Aggregation of CaCO3 particles in PP composites: Effect of surface coating. Composites Science and Technology, 67, 1574-1583 (2007).

[45] Ábrányi Á., Százdi L., Pukánszky B., Vancsó G. J., Pukánszky B.: Formation and Detection of Clay Network Structure in Poly(propylene)/Layered Silicate Nanocomposites. Macromolecular Rapid Communications, 27, 132-135 (2006).

[46] Li J., Zhou C., Wang G., Zhao D.: Study on rheological behavior of polypropylene/clay nanocomposites. Journal of Applied Polymer Science, 89, 3609-3617 (2003).

[47] Okamoto M., Morita S., Kim Y. H., Kotaka T., Tateyama H.: Dispersed structure change of smectic clay/poly(methyl methacrylate) nanocomposites by copolymerization with polar comonomers. Polymer, 42, 1201-1206 (2001).

[48] Moussaif N., Groeninckx G.: Nanocomposites based on layered silicate and miscible PVDF/PMMA blends: melt preparation, nanophase morphology and rheological behaviour. Polymer, 44, 7899-7906 (2003).

[49] Okamoto M., Nam P. H., Maiti P., Kotaka T., Hasegawa N., Usuki A.: A house of cards structure in polypropylene/clay nanocomposites under elongational flow. Nano Letters, 1, 295-298 (2001).

[50] Jaber E., Luo H., Li W., Gersappe D.: Network formation in polymer nanocomposites under shear. Soft Matter, 7, 3852-3860 (2011).

[51] Hornsby P.: Rheology, Compounding and Processing of Filled Thermoplastics. in 'Mineral Fillers in Thermoplastics I' (ed.: Jancár J.) Springer-Verlag, Berlin, Vol 139, $155-217(1999)$

[52] Nielsen L. E.: The Thermal and Electrical Conductivity of Two-Phase Systems. 
Industrial \& Engineering Chemistry Fundamentals, 13, 17-20 (1974).

\section{CAPTIONS}

Fig. 1 SEM micrographs showing the particle characteristics of the fibers used; a) large aspect ratio fiber (FT400), b) reference fiber (EFC 1000)

Fig. 2 Composition dependence of the stiffness of PLA/lignocellulosic fiber composites. Symbol: $(\bigcirc)$ reference fiber (EFC 1000), $(\square, \Delta, \nabla)$ large aspect ratio fiber (FT400), parallel series

Fig. 3 Effect of composition on the tensile strength of PLA/wood composites. Symbols are the same as in Fig. 2.

Fig. 4 Reduced tensile strength of PLA/wood composites plotted against fiber content in the representation of Eq. 2; reinforcement and structural effects. Symbols are the same as in Fig. 2.

Fig. 5 Acoustic emission testing of a PLA composite containing 5 vol\% of the FT400 fiber. Small circles indicate individual acoustic events. Stress vs. strain and cumulative no. of signal vs. strain traces.

Fig. 6 Results of the acoustic testing of a PLA/FT400 composite at 50 vol\% fiber content.

Fig. 7 Cumulative number of signal vs. elongation traces for a series of PLA/FT400 composites; effect of fiber content.

Fig. 8 Composition dependence of the initiation stress of the dominating deformation process in PLA/wood composites. Symbols are the same as in Fig. 2.

Fig. 9 POM micrograph recorded on PLA/FT400 composites; a) 5, b) 20, c) 40 vol\% wood. Development of a fiber network at large wood content.

Fig. 10 Effect of fiber content on the equilibrium torque recorded during the homogenization of PLA/wood composites. Symbols: (○) EFC 1000, ( $\square$ ) FT400. 
Faludi, Fig. 1

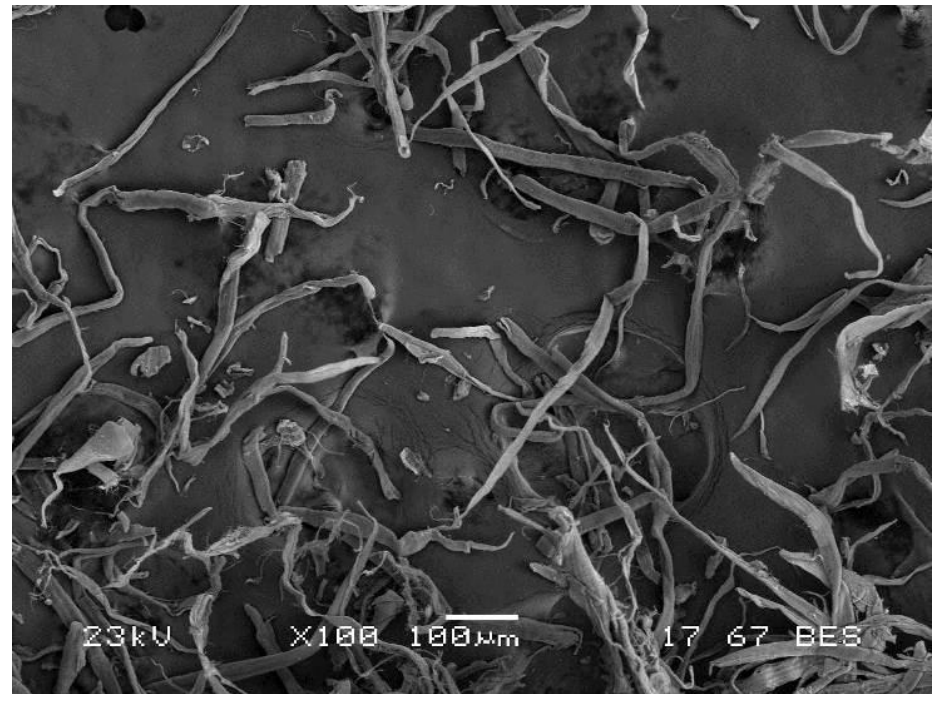

a)

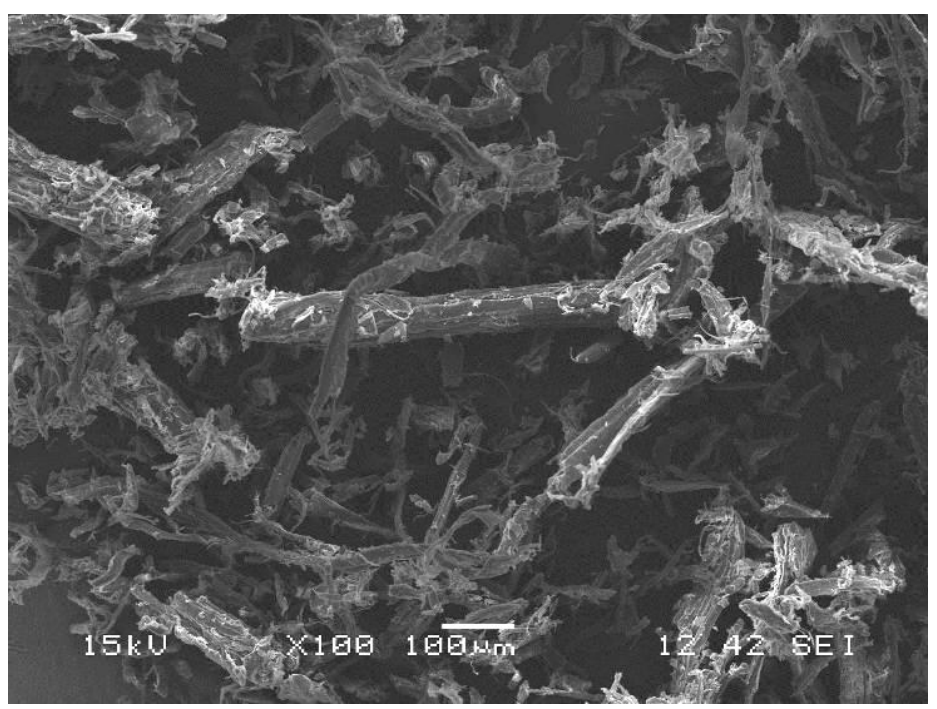

b) 
Faludi, Fig. 2

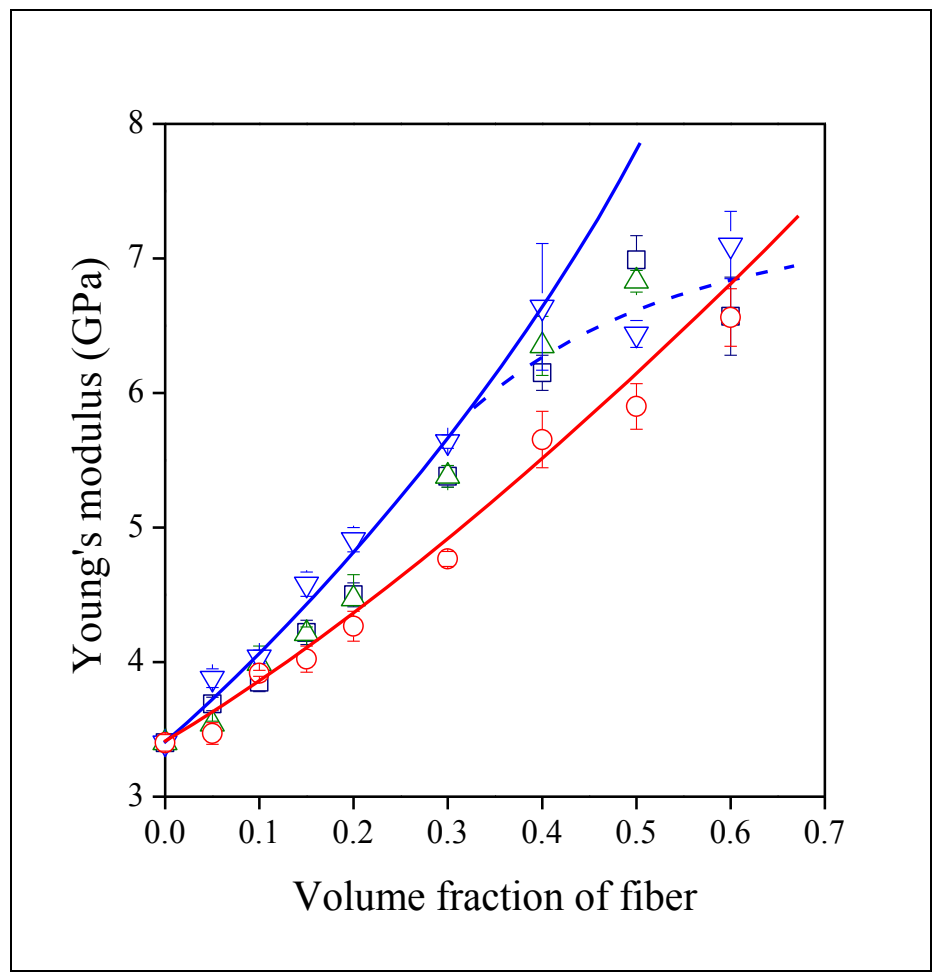

Faludi, Fig. 3

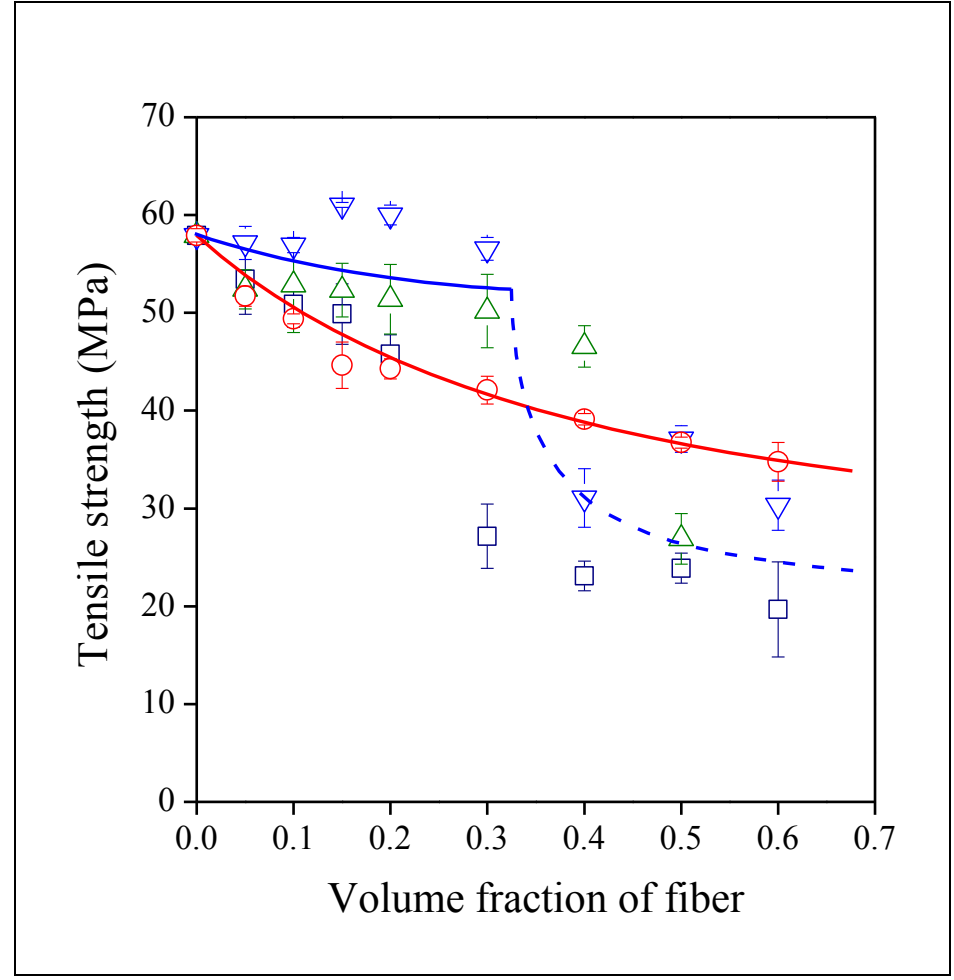


Faludi, Fig. 4

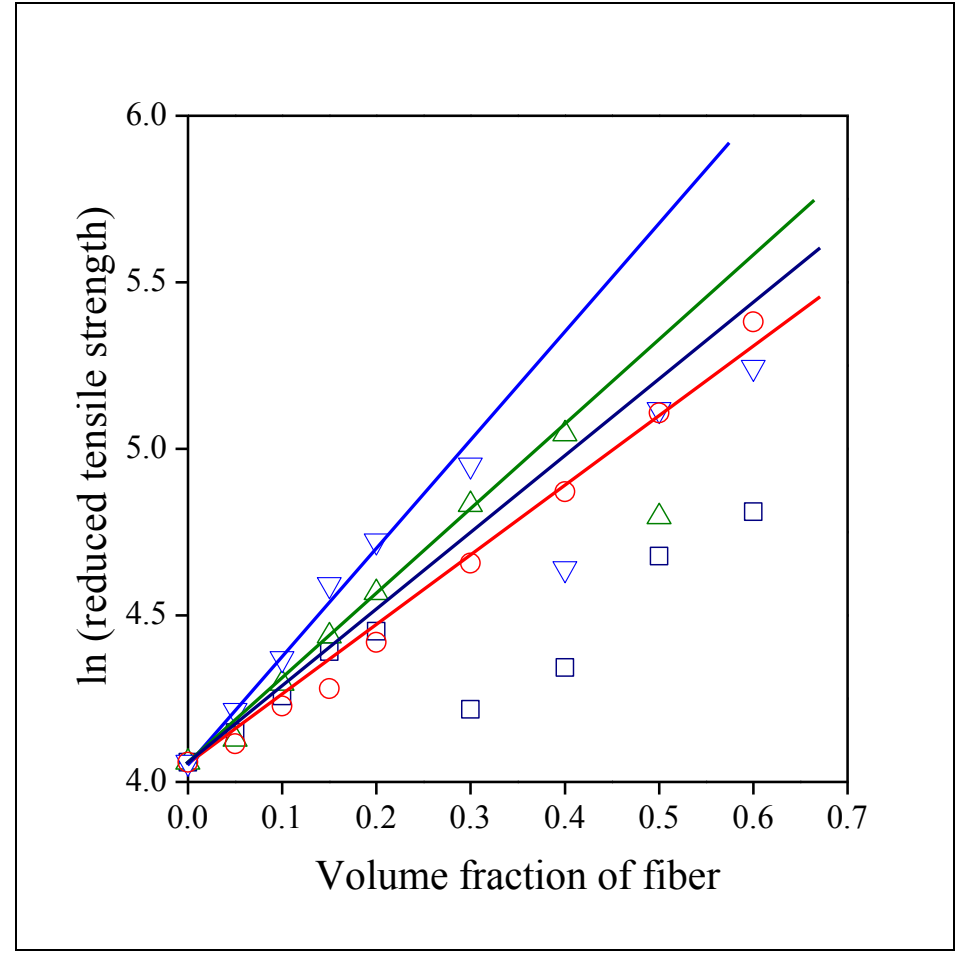

Faludi, Fig. 5

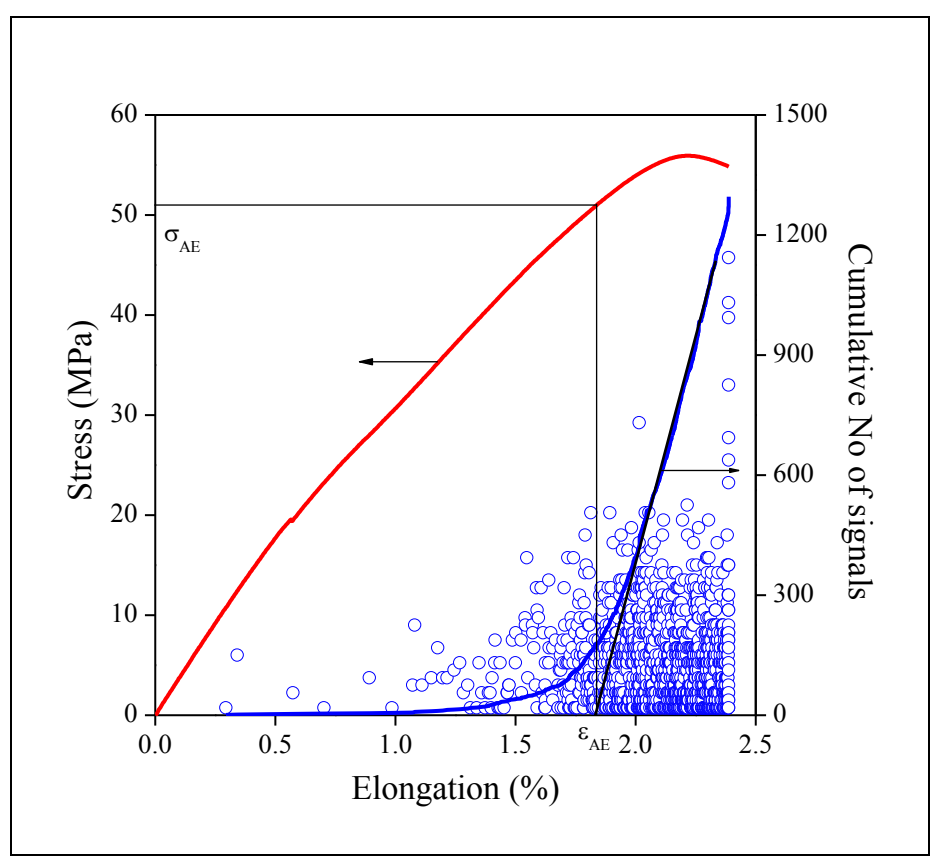


Faludi, Fig. 6

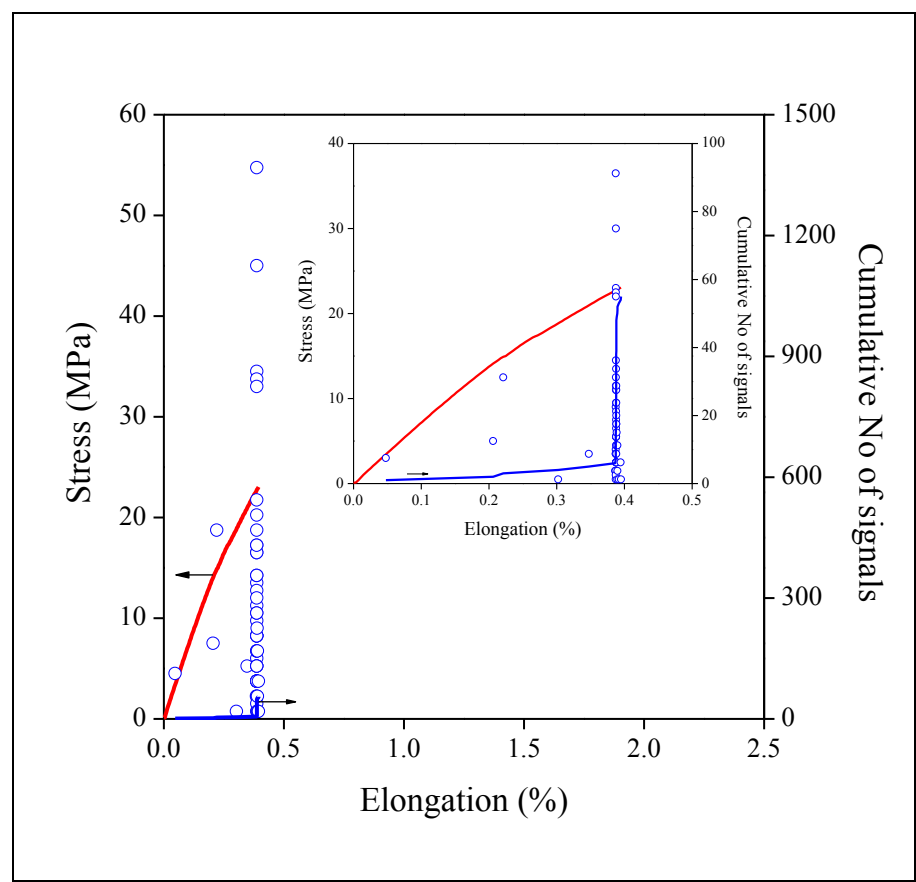

Faludi, Fig. 7

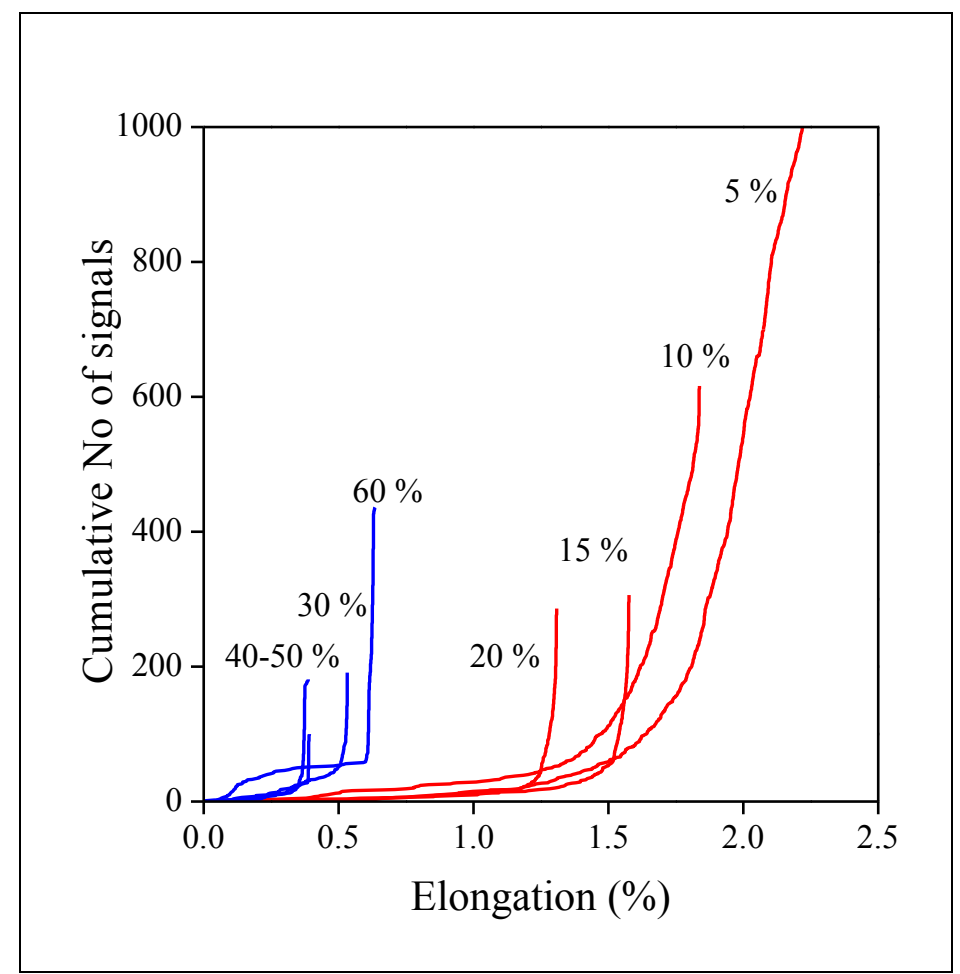


Faludi, Fig. 8

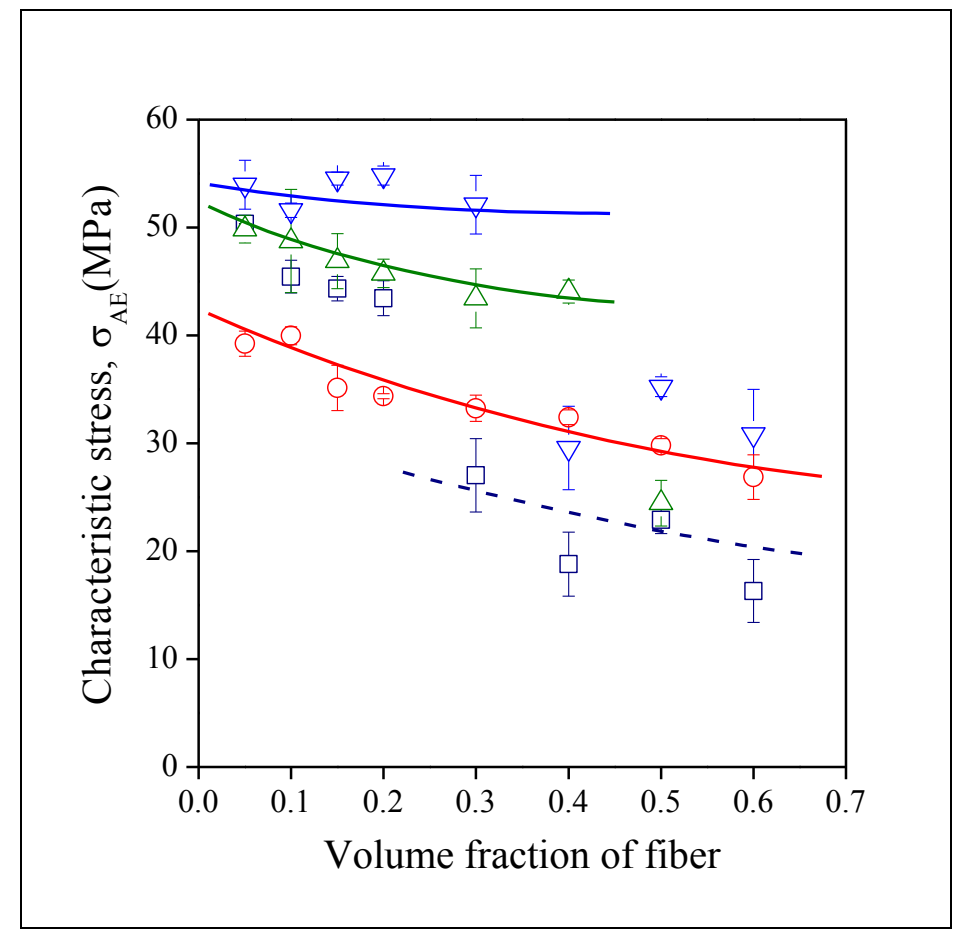


Faludi, Fig. 9

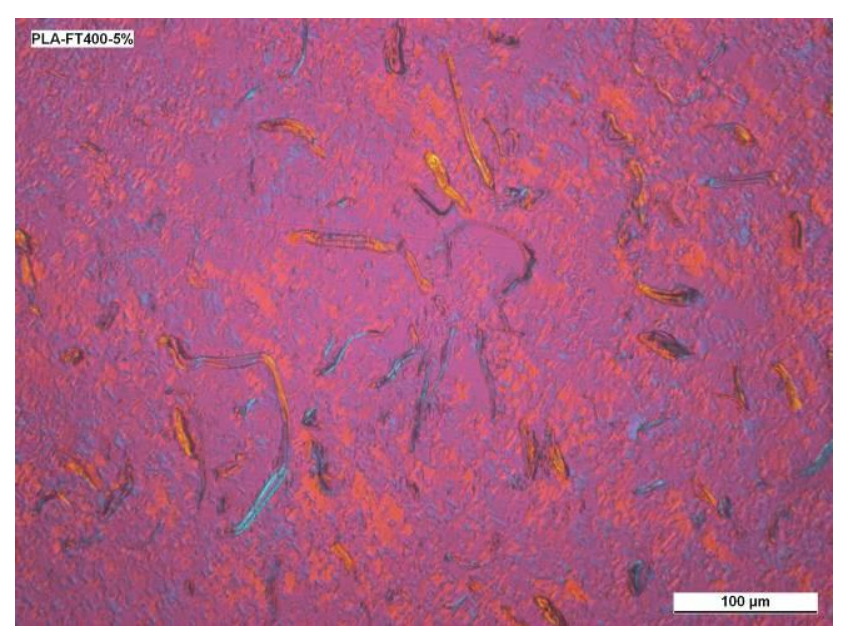

a)

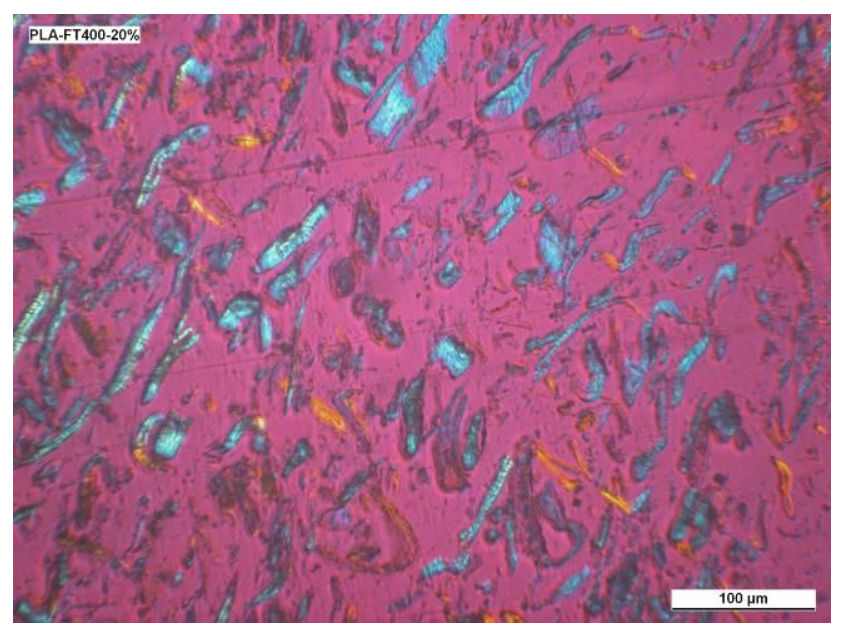

b)

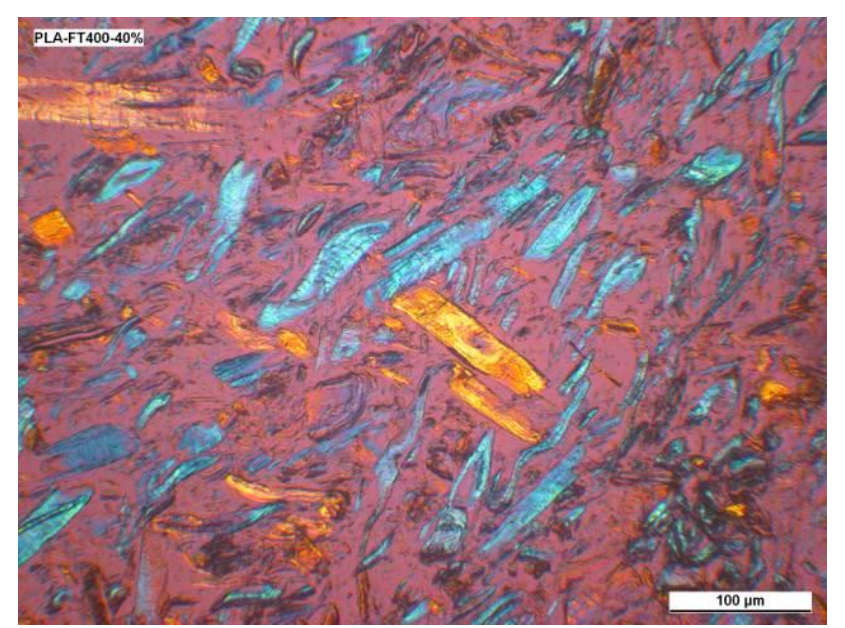

c) 
Faludi, Fig. 10

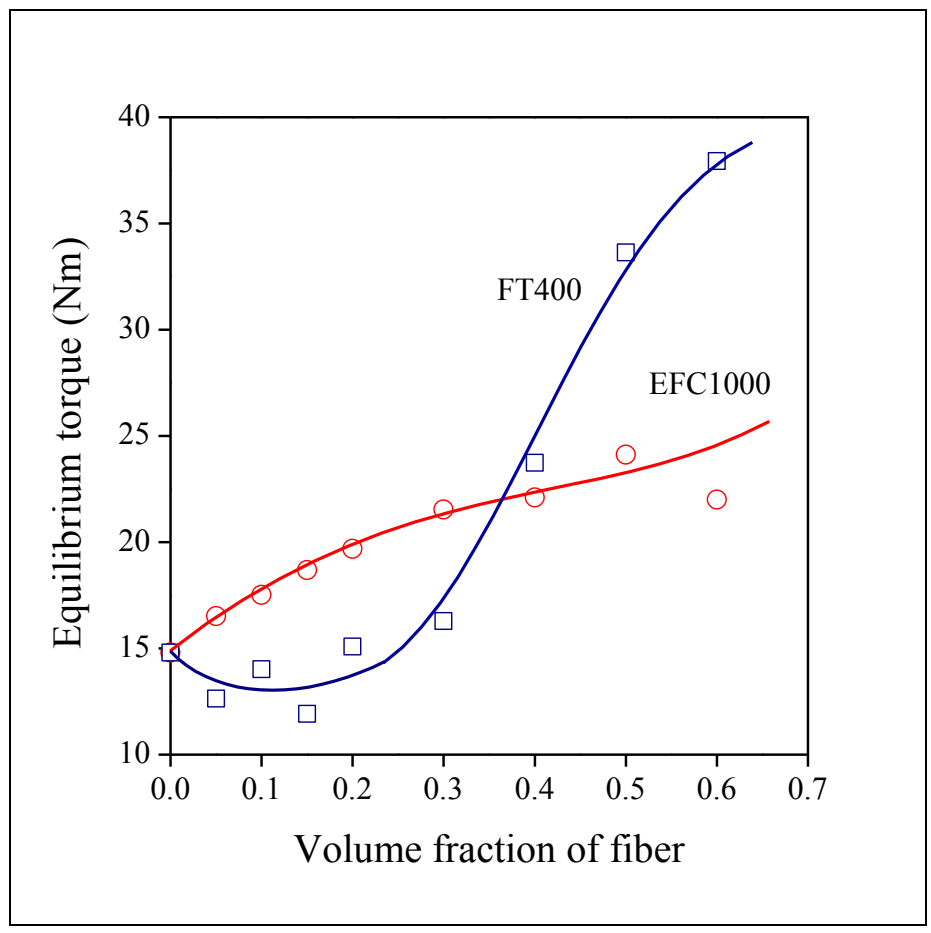

